\title{
Kajian Kelayakan Dry Leaf Board Sebagai Material Akustik Untuk Ruang Hunian
}

\section{Firman Hawari}

Dosen Jurusan Desain Interior, FTSP, Institut Teknologi Sepuluh Nopember

firmanhawari@ymail.com

\begin{abstract}
ABSTRAK
Berdasarkan analisis visual terhadap tekstur permukaan yang licin dan struktur dalam(inner structure) dry leaf board yang berkomposisi silang dan berpori, didapatkan hipotesa mengenai kemungkinan pengembangan potensi dry leaf board sebagai komponen akustik ruang.Tahapantahapan yang akan dilakukan meliputi analisis proses serap gelombang bunyi, ujikemampuan akustik (absorpsi, refleksi, dan insulasi), perencanaan komposisi visual permukaan dan bentuk, evaluasi, revisi, serta kesimpulan.

Kajian ini diharapkan dapat menghasilkan kesimpulan mengenai tingkat kemampuan dry leaf board sebagai material akustik ruang hunian dan tingkat kebisingan (noise level) yang dapat diredam. Keluaran-keluarannya berupa publikasi artikel ilmiah untuk jurnal akreditasi nasional, hak paten, dan juga kegiatan PKM terkait.
\end{abstract}

Kata Kunci : dry leaf board, ruang hunian, material akustik, tingkat kebisingan

\section{ABSTRACT}

Based on visual analysis of the slippery surface texture and composition of inner structure that is cross and porous,obtained hypothesis about possibility of the development of dry leaf board potency as a component of the space acoustic. Stages will be implement are analysis of the absorption process of sound waves, acoustic testing capabilities (absorption, reflection, and insulation), designing surface visual of composition and form, evaluation, revision, and conclusions.

This studyis expected toproduceconclusions aboutlevel of dry leaf board ability as an acoustic material of residential space and noise level can be absorped. An outputs like the publication ofscientific articles for nationalaccredited journals, patent, also small and medium industry development activities.

Key Words :dry leaf board, residential space, acoustic material,noise level

\section{PENDAHULUAN}

Dry leaf board merupakan material baru yang dihasilkan dari kegiatan eksperimen pengolahan daun kering limbah organik di perkotaan. Dry leaf board diciptakan dalam bentuk papan(board) dengan pertimbangan utama yaitu fleksibilitas kemampuan dan kemudahan aplikasi pemanfaatannya. Tujuan awal produksinya adalah sebagai material bangunan yang easy treatment dan easy maintenance. Sampai sejauh ini ketebalan dry leaf board masih dalam kisaran18 mm. Di masa yang akan datang, direncanakan ketebalan papan akan dapat disesuaikan dengan aplikasi pemanfaatannya.

Dasar pemikiran eksperimentasi dry leaf board sebagai material akustik ruang adalah hasil analisis terhadap struktur dalam (inner structure) dry leaf board yang berpori dan tingkat kompleksitas persyaratan akustik kekerasannya.

Sementara ruang hunian dipilih berdasarkan pemikiran bahwa bangunan hunian mempunyai noise level yang terbilang lebih rendah dibandingkan jenis bangunan lainnya. Sesuai dengan tujuan kajian ini yaitu eksperimen awal dry leaf board sebagai material baru sistem akustik ruang. 
Pada banyak teori akustik disebutkan bahwa dalam prinsip akustik ruang, kegiatan pengendalian tingkat kebisingan dapat dilakukan melalui proses refleksi, absorsi, dan insulasi. Proses refleksi adalah memantulkan kembali gelombang bunyi ke obyek awal. Pemasangan komponen pantul sangat mempengaruhi tingkat keberhasilan proses ini. Kesalahan dalam pemasangan akan berakibat pada pemantulan suara ke arah yang tidak dikehendaki. Proses absorpsi adalah proses penyerapan gelombang bunyi. Proses absorpsi hanya efektif terjadi pada permukaan komponen serap saja tetapi tidak untuk menahan gelombang bunyi berfrekuensi rendah dengan kekuatan getar yang hebat. Sementara proses insulasi adalah penggabungan dari proses-proses refleksi dan absorpsi dengan kemampuan serap gelombang bunyi yang jauh lebih besar dibandingkan proses absorpsi [4].

Kajian ini berusaha menemukan berbagai kemungkinan aplikasi prinsip-prinsip absorpsi, refleksi, dan insulasi melalui pemanfaatan dry leaf board. Faktor-faktor tersebut akan menjadi acuan perencanaan struktur dry leaf board di masa yang akan datang. Semua elemen di atas dan tingkat keberhasilan pencapaian standarisasi tingkat kebisingan minimal dalam ruang hunian menjadi acuan tingkat keberhasilan kajian ini.

Secara khusus, kajian ini diharapkan dapat menyumbangkan inovasi dan terobosan baru dalam produksi material sistem akustik nasional danmemberikan peluang peningkatan pendapatan serta kesejahteraan sosial IKM. Sementara secara umum, kajian ini dapat mendukung gerakan green design secara global dengan mengurangi eksplorasi dan pemakaian material-material konvensional serta meningkatkan level kualitas lingkungan di mana manusia berada.

Sebagai material yang relatif baru, dry leaf board belum pernah diuji coba sebagai elemen akustik ruang pada beragam penelitian yang telah dilakukan. Kajian ini lebih difokuskan pada kegiatan eksperimen dan pengujian material dry leaf board sebagai panel akustik ruang hunian untuk menemukan kemampuan fungsi absorpsi, refleksi, dan insulasinya. Pemilihan bentuk panel didasarkan pada pertimbangan efektifitas fungsi akustik dan kemudahan pemasangan. Indikator keberhasilan kajian ini ditandai oleh kemampuan dry leaf board dalam mereduksi tingkat kebisingan dalam ruang hunian seminimal mungkin.

Tujuan dan manfaat dari kajian ini adalah:

1. Menemukan alternatif pemanfaatan dry leaf board sebagai material akustik ruang hunian, baik pada aplikasi prinsip absorpsi, refleksi, ataupun insulasi.

2. Menemukan standar kemampuan dry leaf board sebagai material akustik ruang hunian, terkaitdengan struktur, dimensi, proses aplikasi, dan faktor-faktor pendukung lainnya.

3. Mendapatkan data-data standarisasi pengembangan dry leaf board yang sesuai dengan standarisasi kebutuhan akustik ruang hunian.

\section{METODOLOGI}

Kajianini menggunakan "metode tabung” untuk mengeksperimenkan material dry leaf board sebagai komponen akustik ruang hunian. Metode tabung digunakan untuk mengukur koefisien penyerapan bunyi contoh-contoh bahan akustik yang kecil dan gelombang bunyi merambat tegak lurus pada permukaan contoh bahan tadi. Hasil pengukuran menghasilkan data-data kemampuan penyerapan bunyi dalam jangkauan frekuensi sekitar 200 sampai 3000 Hz. Metode kuantitatif juga digunakan terkait dengan pelaksanaan kegiatan uji lab, untuk menghasilkan data-data lab yang akan dikomparasi dengan standar kebisingan minimum. Ini dilakukan untuk menghasilkan kesimpulan akhirnya itu kemampuan dry leaf board sebagai material akustik ruang hunian. 


\section{A. Tahapan observasi :}

1. Observasi standarisasi sistem akustik dalam ruang.

2. Observasi dan uji laboratorium mengenai struktur dry leaf board terkait dengan potensiakustikyang dimilikinya.

3. Observasi standarisasi sistem akustik pada struktur dry leaf board terkait dengan bentuk, dimensi, tools, komponen, dan sistem proses rangkaian (manufacturing).

4. Perumusan masalah.

5. Analisis untuk lebih memahami dan mendalami aplikasi dry leaf board sebagai material sistem akustik.

\section{B. Tahapan Eksperimen}

1. Analisis produk

Uji kelayakan :

a) Uji laboratorium,

b) Uji lapangan untuk mengetahui kesesuaian bentuk prototype dengan fungsinya serta manfaatnya padaproyek ruang. Hasil yang diharapkan adalah nilai kelayakan standarisasi fungsi.

2. Analisis kegiatan eksperimen dilakukan secara kualitatif dan kuantitatif untuk mengetahui permasalahan yang terjadi dan memperbaikinya pada kegiatan berikutnya.

\section{Pasca Eksperimen}

1. Mengevaluasi dan membuat kesimpulan mengenai kegiatan riset secara keseluruhan sebagai asumsi akhir mengenai kelayakan dry leaf board sebagai material akustik ruang.

2. Penulisan kajian secara keseluruhan secara lengkap dan sistematik.

\section{EKSPERIMEN}

\section{A. Eksperimen Akustik}

Karakteristik prototype panel akustikdari material dry leaf board yang disiapkan sebagai specimen uji untuk penelitian ini mempunyai dimensinya : diameter $9.8 \mathrm{~cm}$ dan tebal $2.38 \mathrm{~cm}$. Gambarnya sebagai berikut :

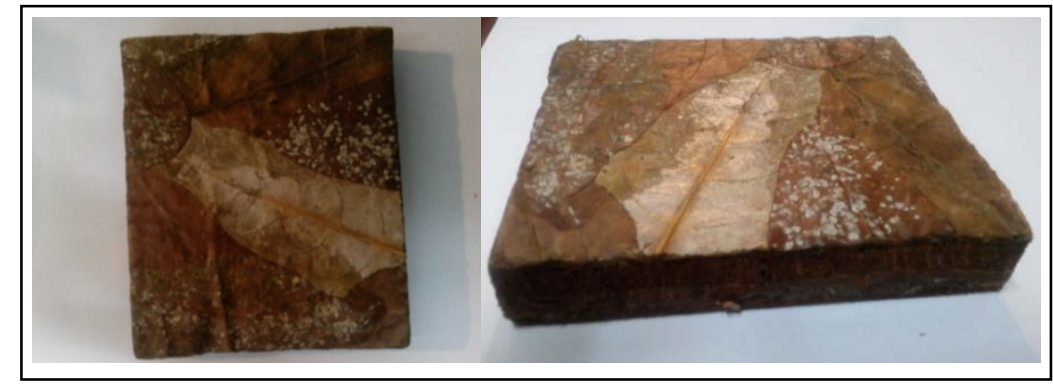

Gambar 1. Material Dry Leaf Board sebagai Spesimen Uji Sumber : Dokumentasi Penulis (2015) 
Tahapan uji yang telah dilakukan, antara lain :

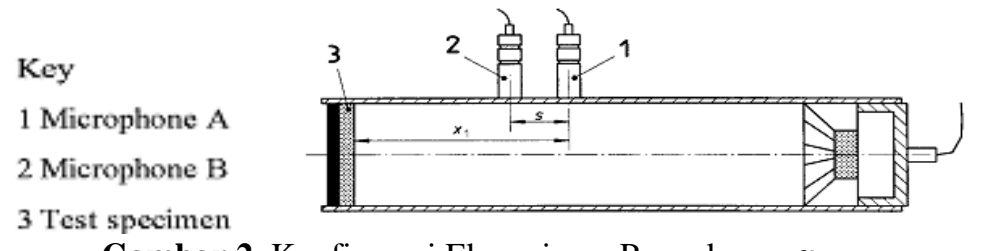

Gambar 2. Konfigurasi Eksperimen Pengukuran $\alpha$ Sumber :Konstruksi Penulis (2015)

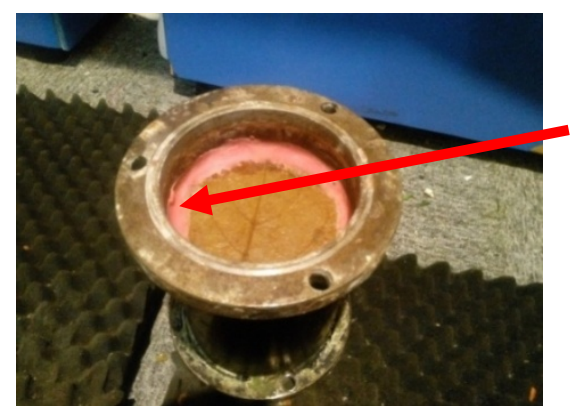

Dry leaf board

Gambar 3. Peletakan Spesimen Uji

Sumber : Dokumentasi Penulis (2015)

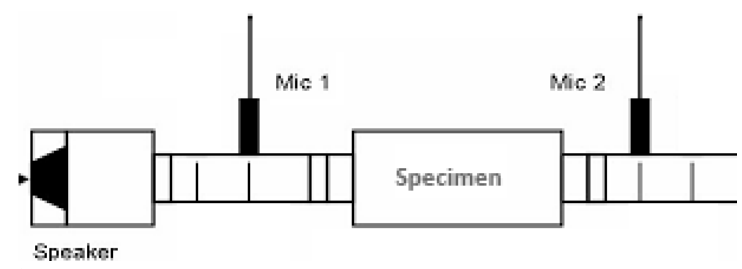

Gambar 4. Konfigurasi Eksperimen Pengukuran $T L$ Sumber : Konstruksi Penulis (2015)

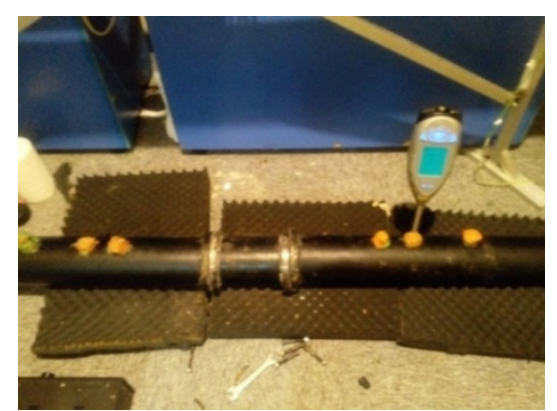

Gambar 5. Pengukuran TTB pada Tiap Daerah Tabung Impedansi Sumber : Dokumentasi Penulis (2015)

\section{HASIL}

Dari beberapa tahapan uji akustik yang telah dilakukan di Laboratorium Rekayasa Akustik dan Fisika Bangunan, Jurusan Teknik Fisika, FTI - ITS, maka didapatkan hasil pengujian akustik dari spesimen dry leaf board adalah sebagai berikut:

1. Koefisien Serap $(\alpha)$

Dari pengukuran koefisien alpha pada specimen uji dengan sampel dry leaf board dengan ukuran $\mathrm{t}=2.38 \mathrm{~cm}$ dan diameter $(\varnothing)=9.5 \mathrm{~cm}$, didapatkan hasil pengukuran sebagai berikut: 
Tabel 1. Koefisien Serap Suara $(\alpha)$

\begin{tabular}{|c|c|}
\hline Frequency & $\boldsymbol{\alpha}$ \\
\hline 125 & 0.02 \\
\hline 250 & 0.51 \\
\hline 00 & 0.44 \\
\hline 1000 & 0.28 \\
\hline 2000 & 0.27 \\
\hline 4000 & 0.07 \\
\hline
\end{tabular}

Sumber : Hasil Eksperimen (2015)

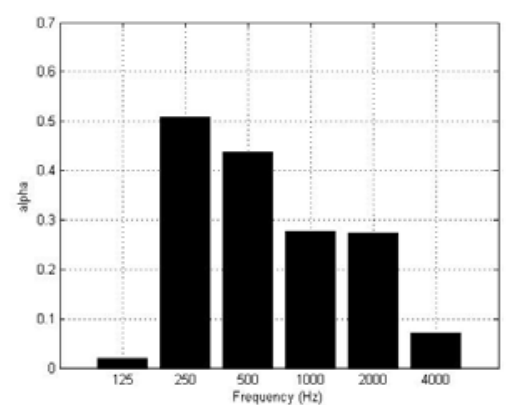

Gambar 6. Grafik Koefisien Serap Suara Spesimen Uji Sumber : Hasil Eksperimen (2015)

\section{Transmission Loss}

Dari pengukuran UjiTransmission Loss pada specimen dry leaf board dengan ukuran $\mathrm{t}=2.38 \mathrm{~cm}$ dan diameter $(\varnothing)=9.5 \mathrm{~cm}$, didapatkan hasil pengukuran sebagai berikut:

Tabel 2. Transmission Loss SpesimenUji

\begin{tabular}{|c|c|}
\hline $\begin{array}{c}\text { Frequency } \\
\text { (Hz) }\end{array}$ & $\begin{array}{c}\text { Transmission } \\
\text { Loss (dB) }\end{array}$ \\
\hline 125 & 82.8 \\
\hline 160 & 54.5 \\
\hline 200 & 61.9 \\
\hline 250 & 52.3 \\
\hline 315 & 47.8 \\
\hline 400 & 62.7 \\
\hline 500 & 57.9 \\
\hline 630 & 62.4 \\
\hline 800 & 46.2 \\
\hline 1000 & 53.3 \\
\hline 1250 & 44.7 \\
\hline 1600 & 41.1 \\
\hline 2000 & 40.1 \\
\hline 2500 & 37.7 \\
\hline 3150 & 57.1 \\
\hline 4000 & 63,2 \\
\hline STC & 401 \\
\hline
\end{tabular}

Sumber : Hasil Eksperimen (2015)

Hasil kedua uji kemampuan akustik tersebut menunjukkan bahwa material dry leaf board mempunyai kemampuan meredam suara dengan baik pada bagian mid-frequency (under 125 $\mathrm{Hz}$ ). Namun pada pengujian frekuensi $125 \mathrm{~Hz}$ dan $2000 \mathrm{~Hz}$ menunjukkan bahwa material dry leaf board memiliki kemampuan daya serap suara yang rendah. Oleh karena itu, dapat disimpulkan bahwa penggunaan material dry leaf board sebagai peredam dalam aplikasi ruangan speech akan menghasilkan performa yang baik, tetapi kurang cocok diaplikasikan sebagai bahan peredam bagi aplikasi ruang studio musik. 


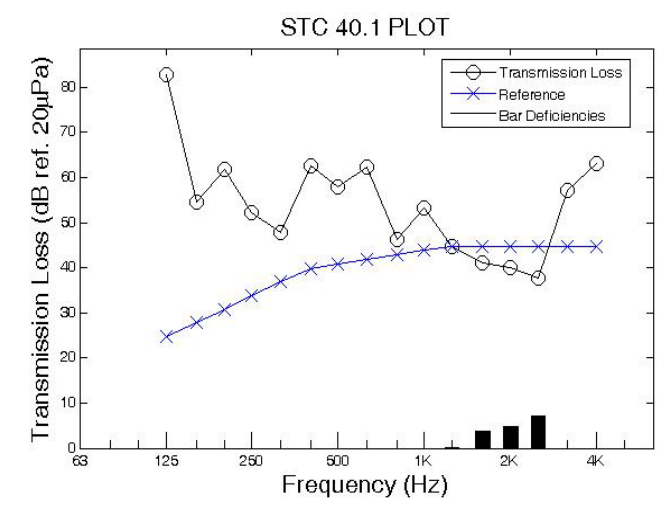

Gambar 7. Grafik Transmission Loss Spesimen Uji Sumber : Hasil Eksperimen (2015)

\section{KESIMPULAN}

Jadi pada akhirnya, permasalahan yang terkait dengan kemampuan material dry leafboard sebagai panel akustik ruang telah diketahui jawabannya. Melalui serangkaian uji eksperimen akustik, yang meliputi uji koefisien serap suara dan transmission loss, dapat disimpulkan bahwa material dry leaf board mempunyai kemampuan akustik yang baik untuk ruangan speech dengan karakter low-mid frequency. Sedangkan untuk ruang-ruang dengan karakter high frequency $(125 \mathrm{~Hz}-2000 \mathrm{~Hz})$ seperti studio musik, bioskop, dan sejenisnya, dry leaf board masihbelum dapat berfungsi akustik dengan baik.

Oleh karena itu, kajian ini dengan tema eksplorasi dry leaf board sebagai material akustik sudah berhasil mencapai hasil yang diharapkan. Semoga hasil kajian ini dapat memberikan manfaat yang sebesar-besarnya bagi perkembangan teknologi dan umat manusia secara keseluruhan.

\section{DAFTAR PUSTAKA}

[1] Buchanan, Richard and Margolin, Victor. (1995). Discovering Design. Chicago. USA : The University of Chicago Press

[2] Doelle, Leslie L. (alih bahasa : Lea Prasetio). (1972). Environmental Acoustic. England : McGraw-Hill.

[3] Long, Marshall. 2006. Architectural Acoustic: Sound Transmission Loss. Elsevier Academic Press

[4] Mediastika, Christina E. 2005. Akustika Bangunan. Jakarta : Penerbit Erlangga.

[5] Pevsner, Nikolaus. 1968. The sources of Modern Architecture and Design. London. UK : Thames and Hudson Ltd

[6] Sparke, Penny. 1986. An Introduction to DESIGN \& CULTURE in the Twentieth Century. London. UK : Allen \& Unwin Ltd

[7] Thomas F. Döring; Marco Archetti; Jim Hardie (2009), Autumn leaves seen through herbivore eyes,Proceedings of the Royal Society B Biological Sciences, London, Published by Thames and Hudson

[8] Undang Ahmad Basuki. (1992). Penuntun Praktikum, SISTEMATIK TUMBUHAN TINGGI. Bandung. Indonesia. Pusat Antar Universitas. ITB

[9] Widagdo. (2000). Desain dan Kebudayaan. Bandung : Penerbit ITB

[10] Yasraf Amir Pilliang. (2009). Materi mata kuliah Desain dan Kebudayaan 2. Bandung: ITB 